\title{
PV Characterization System Outdoors-Case Study in Brazil
}

\author{
Pedro Rodrigues Silva, Patrícia Romeiro da Silva Jota, Ana Paula Batista \\ Research Center of Smart Energy, Electrical Engineer Department, Federal Centre of Technological Education (CEFET-MG), \\ Belo Horizonte, Brazil \\ Email: prsjota@cefetmg.br
}

How to cite this paper: Silva, P.R., da Silva Jota, P.R. and Batista, A.P. (2017) PV Characterization System Outdoors-Case Study in Brazil. Journal of Power and Energy Engineering, 5, 119-132.

https://doi.org/10.4236/jpee.2017.512014

Received: November 16, 2017

Accepted: December 26, 2017

Published: December 29, 2017

Copyright ( $) 2017$ by authors and Scientific Research Publishing Inc. This work is licensed under the Creative Commons Attribution International License (CC BY 4.0).

http://creativecommons.org/licenses/by/4.0/

(c) (i) Open Access

\begin{abstract}
Photovoltaic modules (PV) are tested in the industry in standard conditions and their characteristics are given in the datasheet. After installation on the site, its performance is not evaluated separately of the other parts of the PV generator. Nevertheless some discrepancies of the expected generation and the measured ones are verified. To deal with these discrepancies it is worth characterizing the module on the site and acquire data in an easy and inexpensive way. This paper presents a proposed characterization system as well as its application. A module test was performed on a site located in Brazil. At these latitudes it is common to have high amount of ultraviolet components. The characterization system measures separately the ultraviolet component, as well as the visible and global irradiations. The results obtained are analyzed and the effect of the UV variation is observed, proving the importance of doing this characterization on site after implementation of the PV system.
\end{abstract}

\section{Keywords}

Photovoltaic, Solar Spectrum, Ultraviolet

\section{Introduction}

The PV characterization is an emerging theme that has attracted the attention of many researchers recently, since PV systems are expanding worldwide. The PV characterization under real operating conditions is still a challenge. The high costs of the characterization systems and the difficulty in measuring of the large number of variables involved in the process are factors that make it difficult. Generally, the PV modules are tested by producers based on the Standard Test Conditions (STC). According to International Electrotechnical Commission standard (IEC-60904:3), the PV module has to be tested in a lab with tempera- 
ture equal to $25^{\circ} \mathrm{C}$, standard irradiation equal to $1000 \mathrm{~W} / \mathrm{m}^{2}$ and air mass (AM) equal to $1.5 \mathrm{G}$. However this condition is rarely observed in real conditions during the PV operation. To better understand the PV module performance it is interesting to test it in real conditions, where it will be applied. In this context, several researches have been proposed aiming to find methodologies for characterization that allow a systemic analysis of PV performance. Using models, one can predict the production of the module, but to validate the used model it is necessary to test it in different conditions of the environmental variables. The extraterrestrial solar radiation is the same in any part of the Earth, but as the atmosphere characteristics are different, the terrestrial radiation became different. The spectrum of the composition of the solar radiation is filtered differently depending on the composition of the atmosphere. Even at the same location, the effects of the atmosphere on the dispersion and absorption of radiation are variable with time as atmospheric conditions and air mass change [1]. There are different irradiation models for clear sky and others for cloudy sky. However these models calculate the total solar radiation but not the sun composition. Although that, the PV model is considered the same for different compositions of the sun.

As PV use grows all over the world, the PV module building integrated becomes common. This integration affects the working conditions and can produce significant interferences in their operation. It is emphasized that the orientation and the surface slope must be carefully evaluated, taking into account, in addition to the architectural issues, the cost of the panels and the effective generation of energy. The best application of PV module is obtained when it is installed on a tracker with two axes, which tracks the sun by moving in prescribed ways to minimize the angle of incidence of beam radiation on their surfaces and thus to maximize the incident beam radiation. As a consequence it is possible to maximize the generated energy. Due to the maintenance needs of these trackers, their application is rare in buildings. Alternatively, PV modules are fixed and their position has to maximize the energy production during a year. It was proved that the best orientation azimuth has to be north in the southern hemisphere and south in northern hemisphere. The inclination should be chosen considering the latitude of the location. The best inclination is near the latitude angle. However, in real cases, when there is a roof in the top of the building, the azimuth and inclination are chosen to be the ones of the own roof. In these cases, PV system does not produce as expected. Another important effect is the shade effect. If there is any shadow during the year, it has to be analyzed.

As some people have doubt that the PV system is a good investment, the forecast of energy production has to be considered with special care. To better forecast the energy production, it is necessary to have a good model for the module. Some methods of energy estimation have been used to forecast the generated energy in specific conditions, de Azevedo Dias et al. [2]. Loschi et al. (2015) [3] presents a solar tracker method review as well as the energy estimation method review. Lacchini et al. (2017) [4] discuss the database influence in 
the estimation of the produced energy and as a consequence in payback returns. It has been shown that there are payback differences of $23 \%$ when different databases are used, such as Solar and Wind Resource Assessment (SWERA) and PVsyst. Pavan et al. (2017) [5] present a proposed empirical cell model based on only one diode model. This model was used for some kinds of panels (polycristalline silicon, heterojunction (HIT), copper, indium, gallium, selenium (GIGS) and cadmium and tellurium (CdTe). The simulation using the proposed model calculated using datasheet data is presented and the results are similar to those measured with variations in order to $2 \%$ under irradiation conditions ranging from $900 \mathrm{~W} / \mathrm{m}^{2}$ to $1000 \mathrm{~W} / \mathrm{m}^{2}$. As the model is calculated using the datasheet data, it can be used by the design PV system. However it is necessary to verify if the Pavan conclusion can be applied for different terrestrial irradiation conditions.

To obtain the characteristics of a PV module it is necessary to obtain its IV curve. Regarding the IV curve, Muñoz (2006) [6] described a capacitive method to simulate the load variation in order to obtain the current-voltage curve (IV curve). The capacitance will be charged by the PV module. In the beginning, without charge, the capacitance will accept the short-circuit current. During the charging process, the current will decreases to zero. This capacitance simulates a variable load for the module. The authors inform that fifty points of measurements during the test are necessary to obtain the IV curve with quality. For the tests, the authors have used another model as a reference for measuring temperature and irradiation of the sun. Another important contribution is observed in the study of Spertino et al. (2013) [7]. They analyze the parasite elements effects in PV systems. A modification on the one diode model was proposed to include these elements. The experimental data has been used to validate the proposed model. Fast sampling rate data, $1.25 \mathrm{MS} / \mathrm{s}$, is required to obtain the data during a transient response. This model allows analysis of invertor effects, protections dimension design and grid integration. It is important to guarantee that the radiation is constant during the measurements in real sun condition as some variation may invalidate the results.

To evaluate the obtained parasite parameter quality, real-time tests with changes in radiation during the tests are used, Hishikawa et al. (2016) [8]. It was obtained IV curve measurements during long periods allowing variations of solar radiation. They proved that for IV curves built during a very short period, $200 \mathrm{~ms}$, even during the radiation changes, the measurements present a satisfactory result. Another study, proposed by Pierro et al. (2015) [9], presents a PV characterization modeling procedure in real conditions. In this study there are presented details of sun spectrum variations, irradiation reflection, temperature and others. Hamou et al. (2014) [10] studied real conditions applied in energy performance. They modeled the PV performance considering global irradiation, cell temperature, and air mass. Their results are very similar to those measured. S. Bazyari et al. (2014) [11] analyzes the tracker effects. It is known that tracking 
systems are classified by their motions: single and two axes. A single axis rotation could have any orientation but which in practice is usually horizontal eastwest, horizontal north-south, vertical, or parallel to the Earth's axis [1]. There are equations that allow the designer to calculate how the extraterrestrial radiation will change if trackers are used. But the generation improvement cannot be calculated using this kind of equation as it is applied for extraterrestrial solar radiation. S. Bazyari et al. (2014) [11] presents some test results for the gain obtained using these trackers. Gains of 35\% for one axis and $40 \%$ for two axes are obtained. The authors concluded that for their application, a single axis is indicated because their maintenance costs are lower.

Lin, C.L. (2015) [12] analyzes for methods to improve the energy production of a PV system, which are: more efficient transformer, removing the by-pass diode, water cooling and tracker. It has proven that in total their use can improve the performance in $30.18 \%$, depending on the weather. Concerning module temperature, Abu-Rahmeh, T.M (2017) [13] analyzes different types of cooling technologies. During hot periods, the results become more effective. The best result improves the performance in 5.37\%. The spectrum composition can change the model performance. Rodrigo et al. (2017) [14] present a performance modeling methods review for different solar spectrum. It is shown that even for similar irradiation and temperature variables, the model performance may be different during the year. According to Rodrigo et al., Eke et al. (2017) [15] evaluate the impacts of the spectrum composition variation during a year for cell with bigger gaps, for example: the performance may vary until $15 \%$ for amorphous silicon over a year due to spectrum composition variation.

As many researchers are investigating the performance of the PV systems in real conditions, this study presents a characterization system developed to analyze the performance of PV system in these conditions in a tropical country. As the spectrum composition in tropical area is different from the standard one, the proposed study take three different sun irradiation measurements like ultraviolet, visible and global irradiation. The system consists of different kinds of measurements parts, which use environmental sensors as well as the capacitive method to obtain IV curve. In addition to the experimental data, some computational simulations were performed to obtain the IV curves based on the two diodes model. The real and simulated IV curves have been analyzed.

\section{Experimental Setup}

This section presents a description of the proposed characterization system. The main objective is to build a system that can characterize the PV module under its actual operating conditions. To do this is used compact and commercial components, to make the characterization system cheap and portable as well as replicable. The functions that the system has to operate are: to measure environmental data continually, to simulate a PV load variation to allow measuring the IV curve, the data of the conditioner and the controller. 
The control of the characterization system is done using a built-in evaluation board layout in real time. This is a programmable dispositive that configures input and output accessories devices. It consists of an A/D converter, with 12 bits resolution. An interface has been developed to facilitate the data visualization. They are saved in a bank data for later analysis.

Before designing the system, many different options for building the IV curve were analyzed, as discussed earlier, Duran et al. (2008) [16]. Finally, the capacitive method has been selected due its simplicity. Figure 1 presents a diagram of the diagram of the characterization system. Data is collected using wi-fi dispositive. Then, it is possible to maintain a computer in one place and move only the test part to the module installation place. The built-in dashboard controls the operation of the IV curve tracer. For each programmable time (seconds or minutes), the IV tracer starts another cycle of measurements to obtain a new IV curve. The IV cycle measurements are made during $150 \mathrm{~ms}$, as indicated by Hishikawa et al. (2016) [8]. Environmental data is collected continually without interruption.

Figure 2 presents the proposed test facilities circuit used to obtain the IV curve and the environmental data. A transistor and two relays were used to control the charge and discharge load cycles.

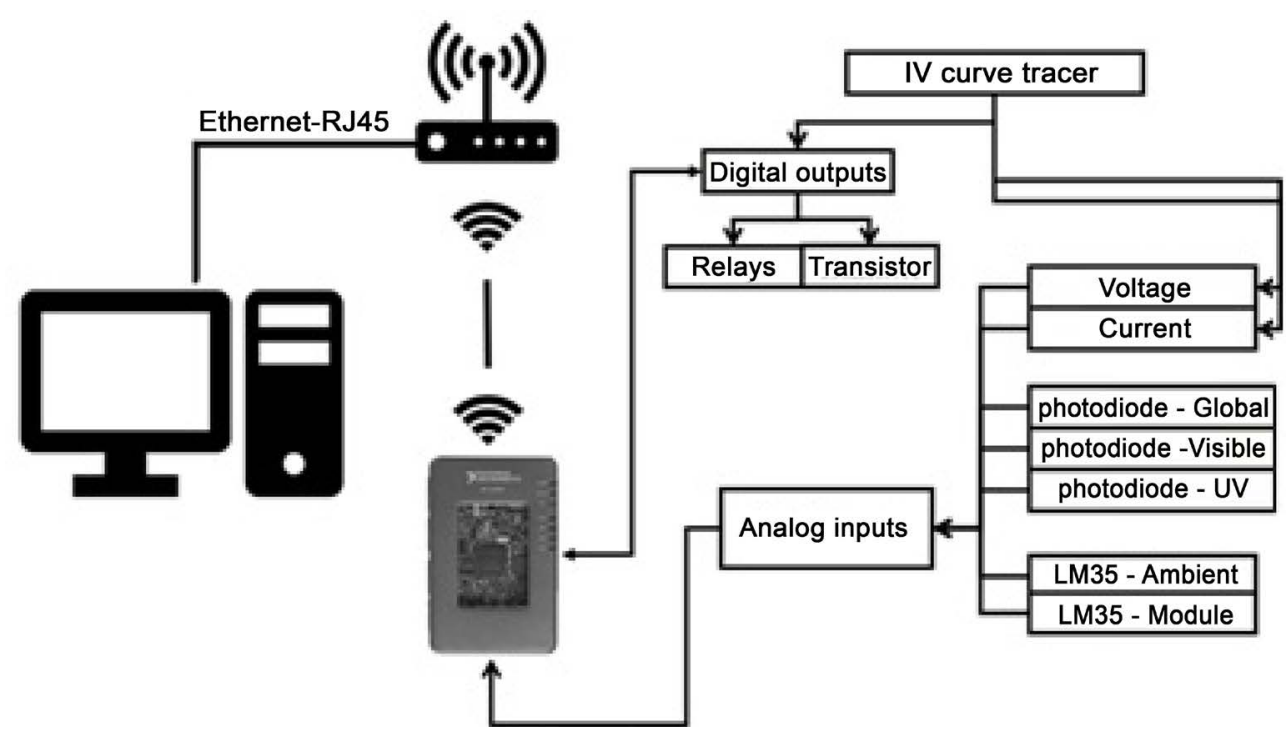

Figure 1. Test facilities.

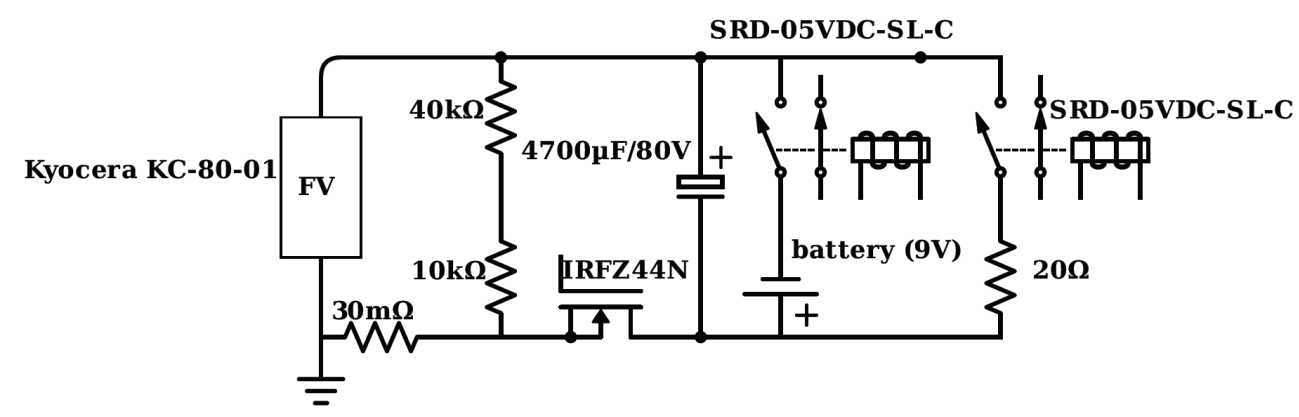

Figure 2. Power circuit. 


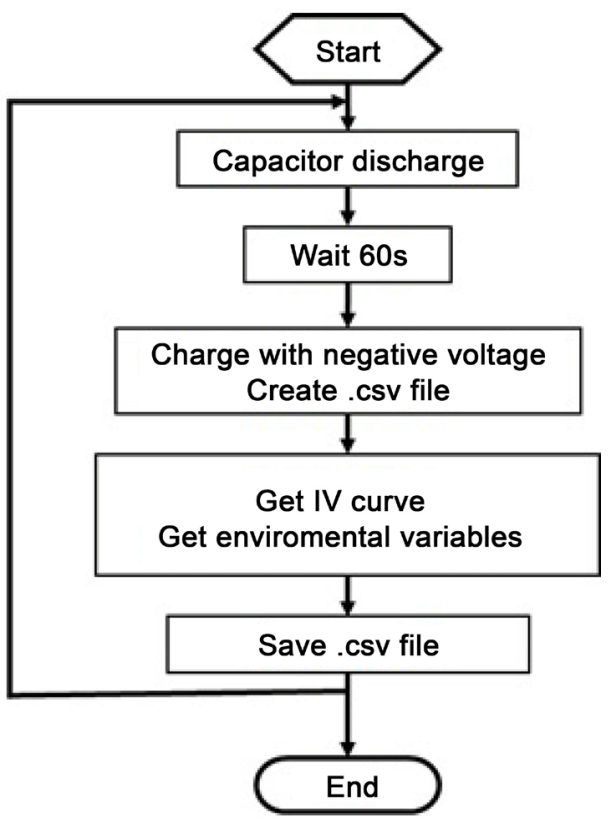

Figure 3. Procedure flowchart.

The real-time embedded evaluation board dispositive is responsible for controlling the transistor and relays, as well as measuring the electric and environmental variables (current, voltage, irradiance and temperature). It has been used the Labview interface to develop the test execution algorithm. Figure 3 presents the flowchart procedure.

\section{Environmental Variables: Solar Spectrum Bands and Temperature}

The characterization system measures the module and ambient temperatures, as well as parts of the spectrum irradiance: ultra-violet (UV), visible spectrum and a global irradiation. These measurements are implemented using commercial sensors and have been calibrated using other instruments or datasheet. The temperature sensor used was the LM 35 with the resolution of $0.5^{\circ} \mathrm{C}$. The spectrum irradiance sensors used were: i) ML8511 for the UV (the output is 10 $\mathrm{mW} / \mathrm{cm}^{2}$ at $365 \mathrm{~nm}$ wavelength which is the point of the maximum sensitivity); ii) BPW21R for the visible spectrum and iii) S1223 for the global irradiation. The output of visible spectrum and a global irradiation sensors were amplified using an IN114 instrumentation amplifier. Figure 4 shows the spectral response of the three sensors applied.

The UV irradiation sensor has been calibrated using its datasheet curve. For the visible irradiation sensor, a light meter was used. Finally, to calibrate the global irradiation sensor, the data collected by a reference weather station was used. As the output of the sensors has small values, signal amplifiers were used, as shown in Figure 5.

All the tests presented in this paper were performed on a KC80-01, $80 \mathrm{~W}$ polycrystalline silicon panel model. Table 1 presents its main datasheet parameters. 


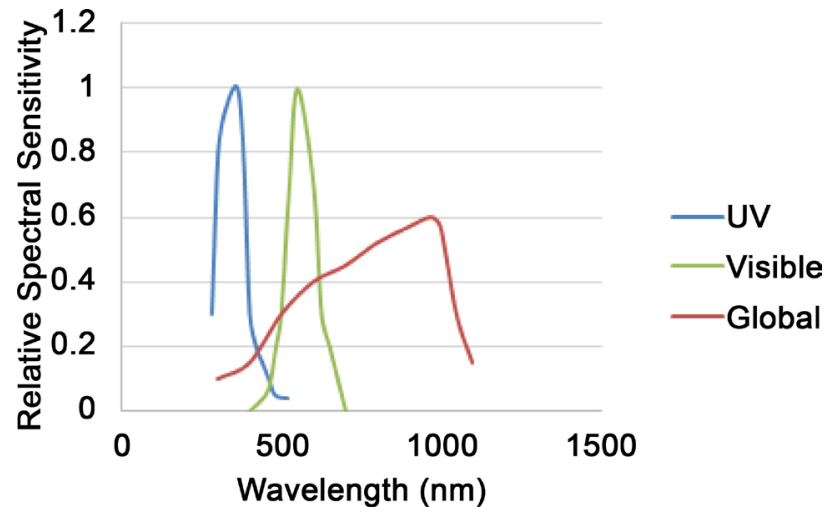

Figure 4. Sensors response.

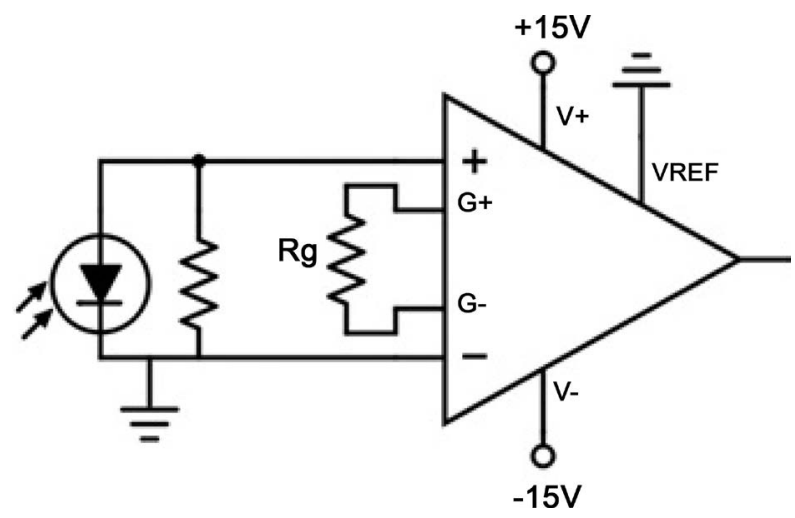

Figure 5. Signal conditioners applied for the photdiodes.

Table 1. Parameters of the photovoltaic module under test.

\begin{tabular}{ccc}
\hline Parameter & Value & Unit \\
\hline Maximum Power & 80 & $\mathrm{~W}$ \\
Maximum Power Voltage & 16.9 & $\mathrm{~V}$ \\
Maximum Power Current & 4.73 & $\mathrm{~A}$ \\
Open Circuit Voltage & 21.5 & $\mathrm{~V}$ \\
Short-Circuit Current & 4.97 & $\mathrm{~A}$ \\
\hline
\end{tabular}

All the tests were performed by using the module in a horizontal position. All the irradiation measures have been made in the same condition. The location of the measurements is: Latitude: $19^{\circ} 55^{\prime} 15^{\prime \prime} \mathrm{S}$, Longitude: $43^{\circ} 56^{\prime} 16^{\prime \prime} \mathrm{W}$. The system collects data automatically for a complete IV curve each $60 \mathrm{~s}$.

As illustrated in Figure 1, the communication between the real-time embedded evaluation device and the computer is done by a wi-fi router. To avoid data missing and communication failure, the computer is connected to the router through the Ethernet connection.

\section{Results and Discussion}

This section presents the results of some tests conducted between June to August 2017. 
In order to analyze this data, many comparisons will be made to verify the importance of characterization of the module on site.

Firstly, the air mass during measurements is presented. The air mass is the ratio of the mass of atmosphere through which beam radiation passes to the mass it would pass through if the sun were at the zenith. When the sun is at the zenith at the sea level, the air mass is 1 . It becomes 2 if the zenith angle $\theta \mathrm{z}$ assumes $60^{\circ}$ [1]. Figure 6 presents the air mass during the tests as functions of the solar time.

It can be observed that the air mass is symmetric during the day, although the measurements have not been carried out symmetrically. Most of the measurements have been done during the afternoons. As expected, the air mass becomes smaller near the noon. Since the measured days were in the autumn, the minimal mass of air obtained was 1.25 .

Figure 7 presents the UV as function of the air mass. It is observed that the air mass has an inverse correlation with the UV. The greater the air mass is, the smaller is the UV. The maximum UV is obtained for the noon time, when the air

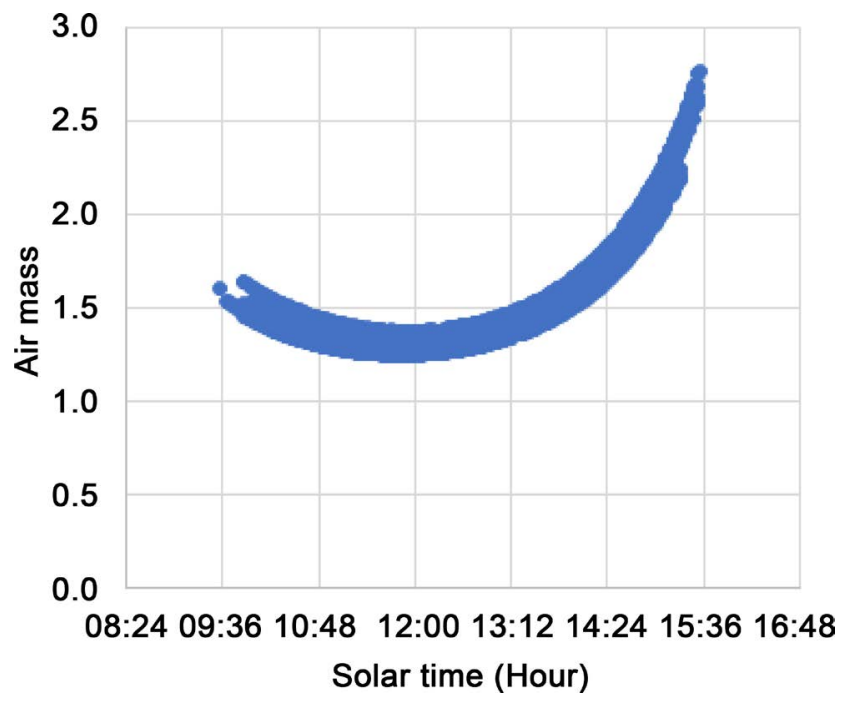

Figure 6. Air mass versus solar time.

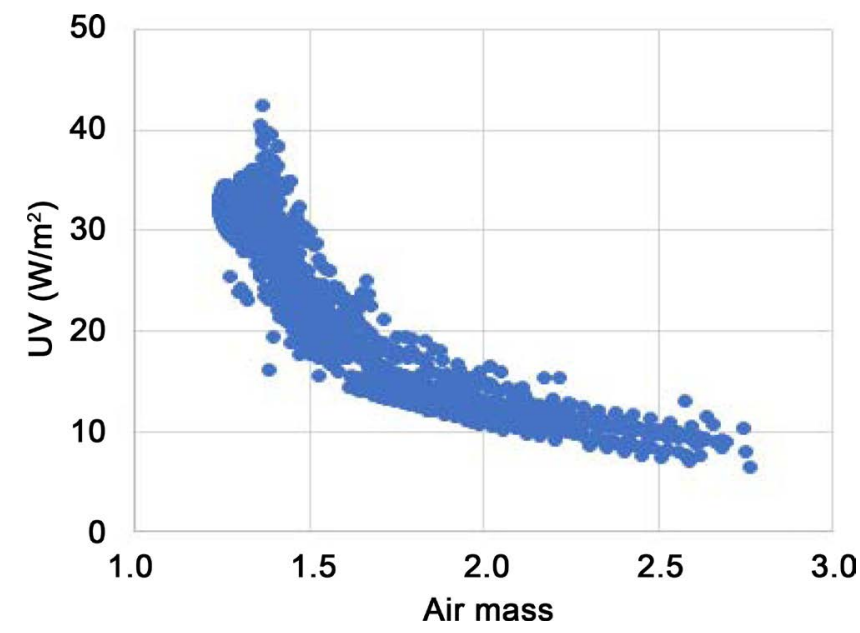

Figure 7. Ultraviolet versus air mass. 
mass reaches its minimum. The UV is filtered by the ozone and the greater the air mass, the greater the ozone layer.

The absorption of the solar energy spectrum radiation in the ultraviolet band is due to the ozone that exists in the atmosphere. For wavelengths below $0.29 \mu \mathrm{m}$ there is almost complete absorption. As $\lambda$ increases above $0.29 \mu \mathrm{m}$ the ozone absorption decreases. For wavelengths greater than $0.35 \mu \mathrm{m}$ there is no absorption [1]. The content of the ozone in the atmosphere depends on the location.

The global irradiation also has an inverse correlation with the air mass, Figure 8. Therefore, comparing both, it is observed that the UV has an abrupt fall until air mass reached 1.5. After that, the reduction is smoother. For the global irradiation, this abrupt drop does not exist, but the UV variation can cause some spreading in the global data. It can conclude that, for air mass smaller than 1.5 the global irradiation has an important contribution from UV irradiation band.

It can be observed in Figure 8 that for air mass smaller than 1.5 the global irradiation is mostly bigger than $600 \mathrm{~W} / \mathrm{m}^{2}$. Comparing the UV and the global irradiation, Figure 9, it can be seen that for global irradiation bigger than 600 $\mathrm{W} / \mathrm{m}^{2}$ the UV grows with greater rate.

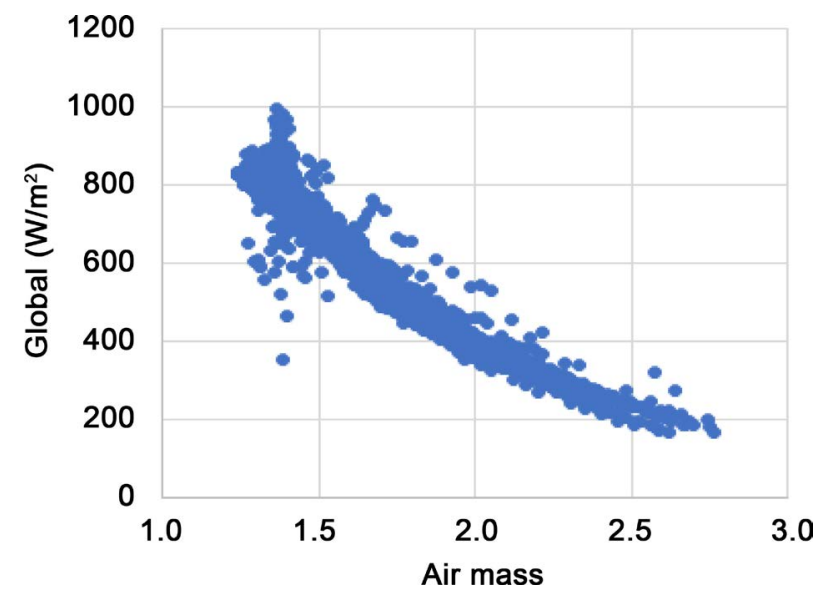

Figure 8. Global versus air mass.

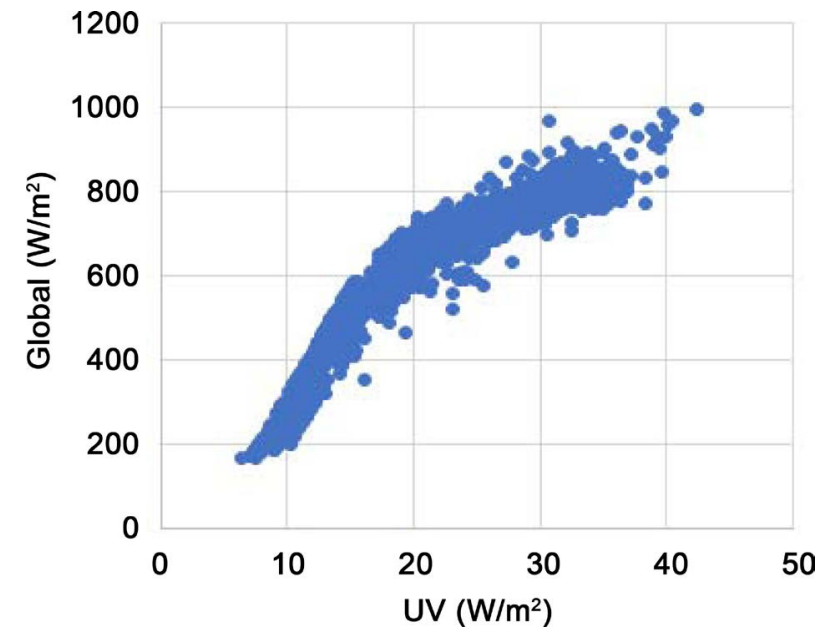

Figure 9. Comparison from UV and global irradiation. 
It can be observed comparing the global and the visible irradiance that their correlation is very high. For global irradiation greater than $600 \mathrm{~W} / \mathrm{m}^{2}$ the UV contribution clearly observed in this graphic in the part with global irradiation greater than $600 \mathrm{~W} / \mathrm{m}^{2}$, Figure 10 .

Figure 11 presents the effect of global irradiation at maximum power. It can be observed that the effect is linear. For irradiance greater than $600 \mathrm{~W} / \mathrm{m}^{2}$, some dispersion can be observed. In order to verify if this dispersion is due to UV, a graphic comparing the maximum power and the UV is presented in Figure 12. Therefore, by analyzing Figure 12, it can be observed that there is a different effect for UV smaller than around 16 and from UV greater than 16. This value of UV corresponds to the medium point for irradiation of $600 \mathrm{~W} / \mathrm{m}^{2}$ observed in Figure 9.

Finally, a general analysis of correlation is done by all variables analyzed. It can be observed that the greater correlation occurs with the two irradiance global

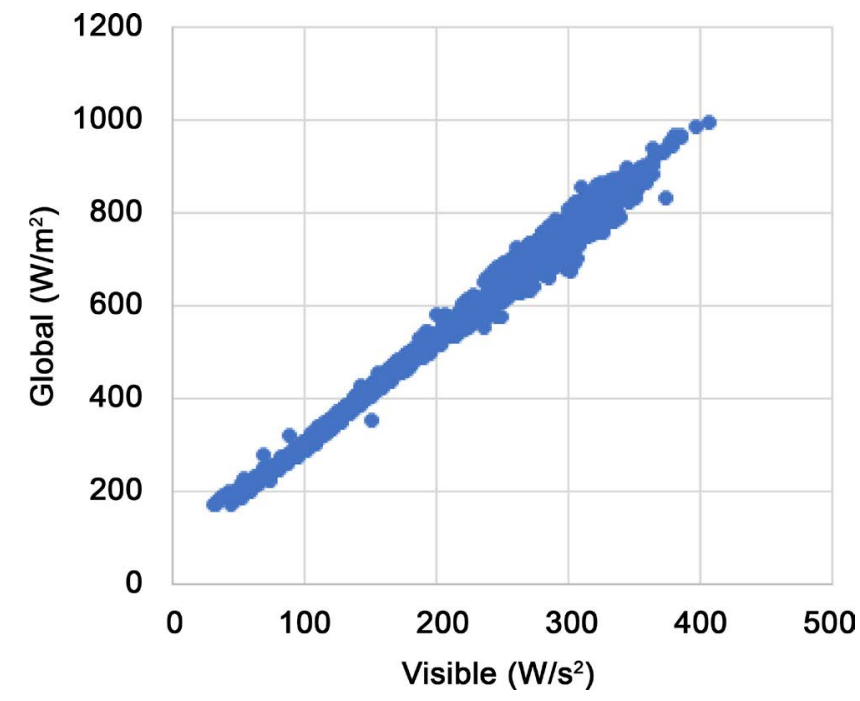

Figure 10. Global irradiation as a function of the visible irradiation.

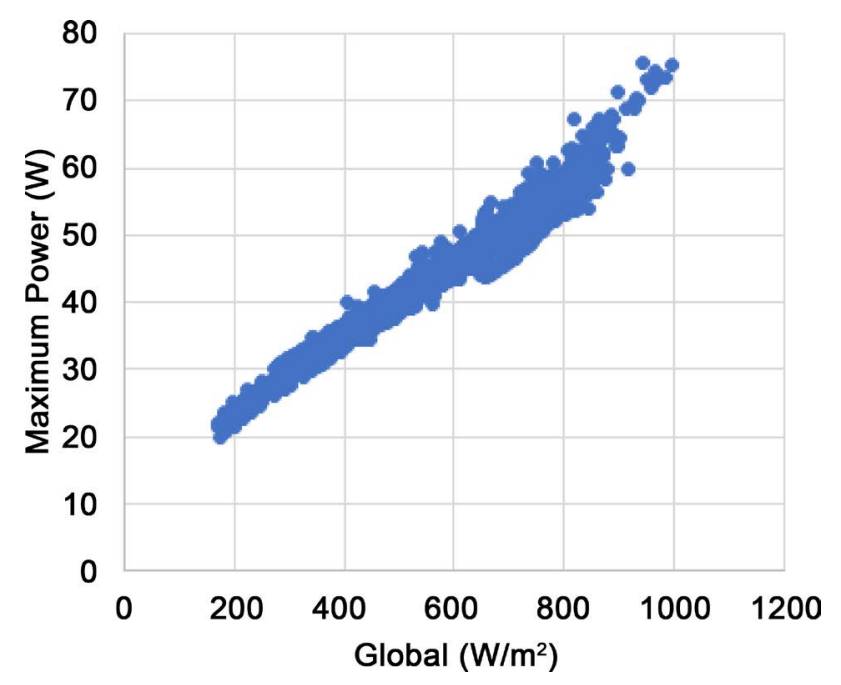

Figure 11. Maximum power measured in function of global radiation. 


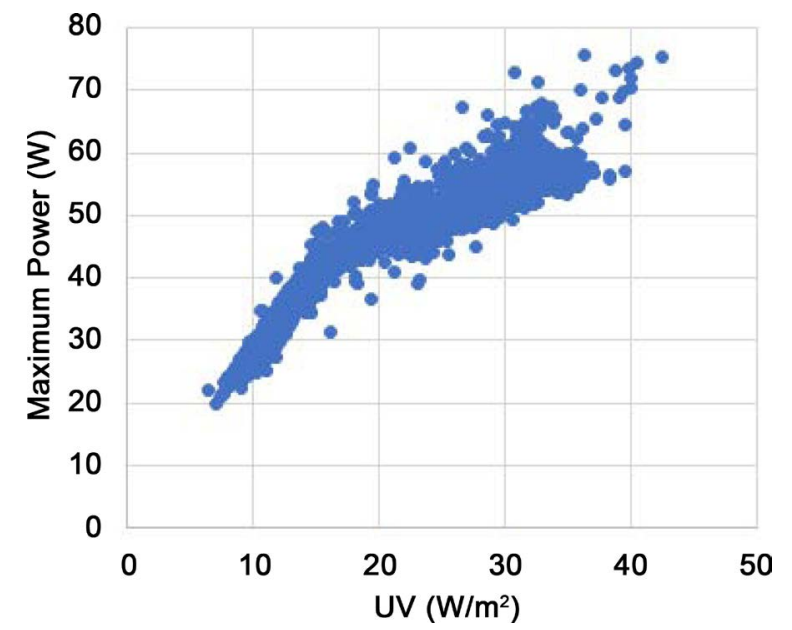

Figure 12. Maximum power measured in function of UV radiation.

Table 2. Correlation coefficients.

\begin{tabular}{|c|c|c|c|c|c|c|c|c|c|c|c|}
\hline & Isc & Voc & Vmp & $\operatorname{Imp}$ & $P \max$ & Global & Vis & UV & Tamb & Tmod & $\mathrm{AM}$ \\
\hline Isc & 1 & 0.22 & -0.50 & 0.99 & 0.99 & 0.98 & 0.98 & 0.94 & 0.13 & 0.63 & -0.94 \\
\hline Voc & & 1 & 0.66 & 0.23 & 0.30 & 0.22 & 0.17 & 0.21 & -0.79 & -0.57 & -0.13 \\
\hline $\mathrm{Vmp}$ & & & 1 & -0.50 & -0.42 & -0.47 & -0.51 & -0.46 & -0.70 & -0.89 & 0.52 \\
\hline $\operatorname{Imp}$ & & & & 1 & 0.99 & 0.98 & 0.98 & 0.93 & 0.11 & 0.62 & -0.94 \\
\hline Pmax & & & & & 1 & 0.98 & 0.98 & 0.93 & 0.05 & 0.57 & -0.93 \\
\hline Global & & & & & & 1 & 0.99 & 0.94 & 0.12 & 0.62 & -0.96 \\
\hline Vis & & & & & & & 1 & 0.94 & 0.17 & 0.66 & -0.97 \\
\hline UV & & & & & & & & 1 & 0.07 & 0.58 & -0.90 \\
\hline Tamb & & & & & & & & & 1 & 0.65 & -0.16 \\
\hline Tmod & & & & & & & & & & 1 & -0.67 \\
\hline AM & & & & & & & & & & & \\
\hline
\end{tabular}

and visible, 0.99 , Table 2 . Temperature is only correlated with the voltage. The higher the temperature is, the smaller is the voltage. It can be observed that the air mass is strongly correlated with many variables.

Figure 13 and Figure 14 present a comparison between the expected IV and PV curves considering the datasheet of the module using a two-diode model and two actual measurements for the same global irradiation. It can be observed that the higher the UV percentage value the higher the short circuit current and maximum power. From what can be reinforce that the modules will produce more energy in the presence of higher UV values even for the same global irradiation.

\section{Conclusions}

The proposed characterization system was developed and tested. It has been developed to allow the characterization of the module in a real condition. The 


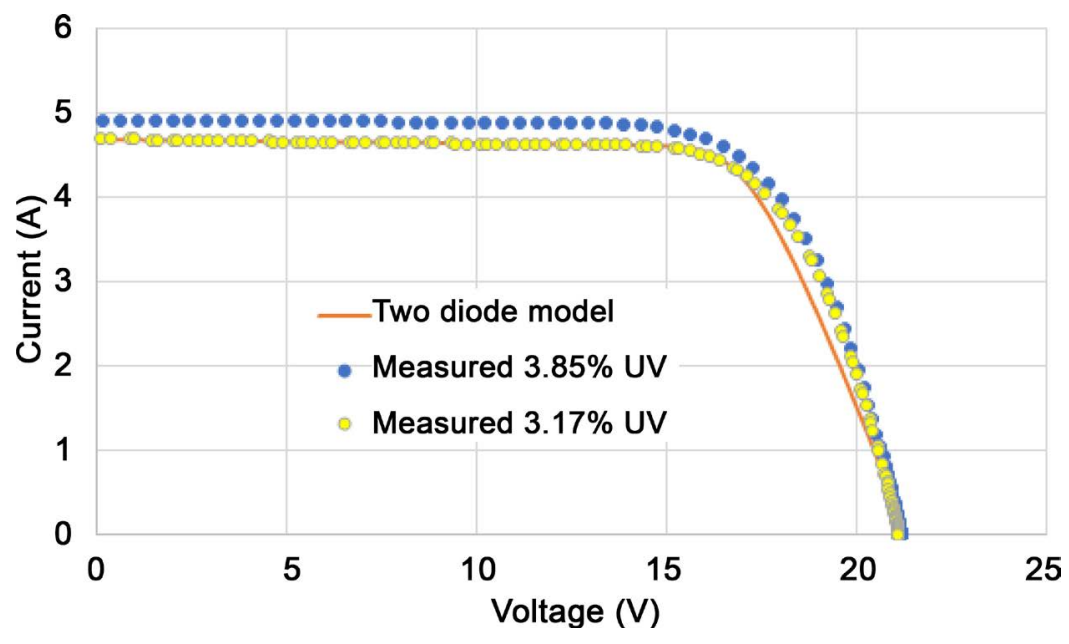

Figure 13. Comparison between the model and measured IV curves.

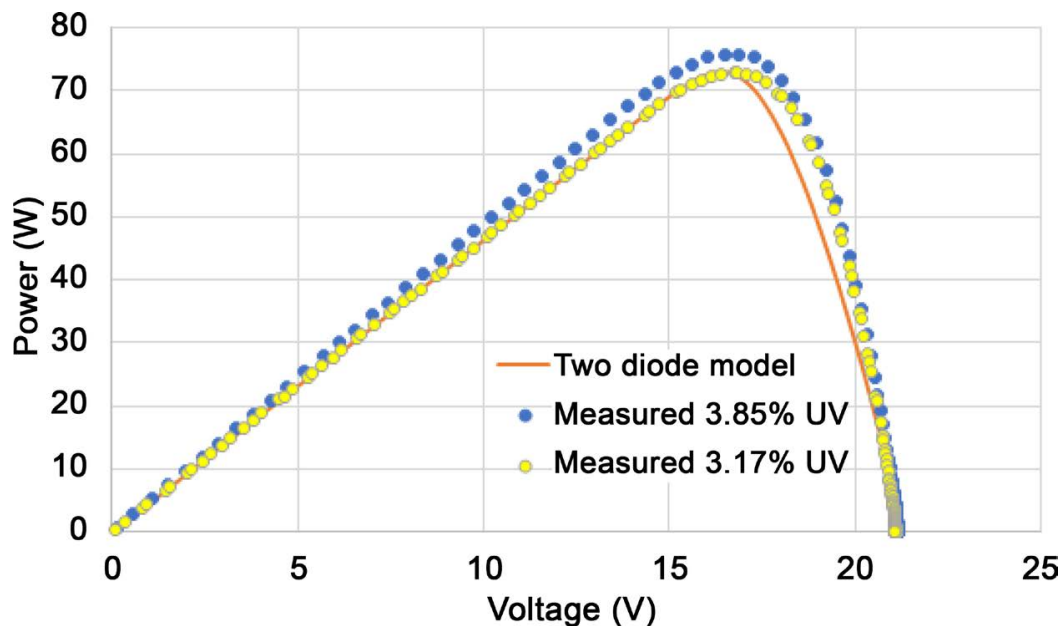

Figure 14. Comparison between the model and measured PV curves.

systems were calibrated and tested. A module was used to be characterized by the developed system. The variables UV, visible and global irradiation, ambient and module temperature along with electrical variables like current and voltage have been measured.

The data obtained during a real operation allow us to observe the technology in a better way. The results can be observed and analyzed. The data obtained for the tested module in Brazil site showed that, when the module is submitted to a real irradiation, the results can present some dispersion depending on the UV composition. Although the UV band does not have many energy compared to the visible one, their variation characteristic changes during the day and the produced power changes consequently. It has been verified that with the same amount of global energy but with more percentage of UV, the produced power increases. This explains the scattering of the data for higher global irradiation, as it occurs for air mass smaller than 1.5 when the UV values are higher.

Finally, the importance of characterization of the module on site is to prove and make it possible to estimate the energy to be generated more accurately. 


\section{References}

[1] Duffie, J.A. and Beckman, W.A. (2013) Solar Engineering of Thermal Processes. John Wiley \& Sons, Hoboken. https://doi.org/10.1002/9781118671603

[2] de Azevedo Dias, C.L., Castelo Branco, D.A., Arouca, M.C. and Loureiro Legey, L.F. (2017) Performance Estimation of Photovoltaic Technologies in Brazil. Renewable Energy, 114, 367-375. https://doi.org/10.1016/j.renene.2017.07.033

[3] Loschi, H.J., Iano, Y., León, J., Moretti, A., Conte, F.D. and Braga, H. (2015) A Review on Photovoltaic Systems: Mechanisms and Methods for Irradiation Tracking and Prediction. Smart Grid and Renewable Energy, 6, 187-208. https://doi.org/10.4236/sgre.2015.67017

[4] Lacchini, C., Antoniolli, A.F. and Rüther, R. (2017) The Influence of Different Irradiation Databases on the Assessment of the Return of Capital Invested in Residential PV Systems Installed in Different Locations of the Brazilian Territory. Solar Energy, 155, 893-901. https://doi.org/10.1016/j.solener.2017.07.004

[5] Massi Pavan, A., Vergura, S., Mellit, A. and Lughi, V. (2017) Explicit Empirical Model for Photovoltaic Devices. Experimental Validation. Solar Energy, 155, 647-653. https://doi.org/10.1016/j.solener.2017.07.002

[6] Muñoz, J. and Lorenzo, E. (2006) Capacitive Load Based on IGBTs for On-Site Characterization of PV Arrays. Solar Energy, 80, 1489-1497.

https://doi.org/10.1016/j.solener.2005.09.013

[7] Spertino, F., Sumaili, J., Andrei, H. and Chicco, G. (2013) PV Module Parameter Characterization from the Transient Charge of an External Capacitor. IEEE Journal of Photovoltaics, 3, 1325-1333. https://doi.org/10.1109/JPHOTOV.2013.2271191

[8] Hishikawa, Y., Doi, T., Higa, M., Yamagoe, K. and Ohshima, H. (2016) Precise Outdoor PV Module Performance Characterization under Unstable Irradiance. IEEE Journal of Photovoltaics, 6, 1221-1227. https://doi.org/10.1109/JPHOTOV.2016.2571620

[9] Pierro, M., Bucci, F. and Cornaro, C. (2014) Full Characterization of Photovoltaic Modules in Real Operating Conditions: Theoretical Model, Measurement Method and Results. Progress in Photovoltaics: Research and Applications, 23, 443-461. https://doi.org/10.1002/pip.2450

[10] Hamou, S., Zine, S. and Abdellah, R. (2014) Efficiency of PV Module under Real Working Conditions. Energy Procedia, 50, 553-558. https://doi.org/10.1016/j.egypro.2014.06.067

[11] Bazyari, S., Keypour, R., Farhangi, S., Ghaedi, A. and Bazyari, K. (2014). A Study on the Effects of Solar Tracking Systems on the Performance of Photovoltaic Power Plants. Journal of Power and Energy Engineering, 2, 718-728. https://doi.org/10.4236/jpee.2014.24096

[12] Lin, C.-L. (2015) Case Study of Solar Power Producing Efficiency from a Photovoltaic System. Open Journal of Energy Efficiency, 4, 45-52. https://doi.org/10.4236/ojee.2015.43005

[13] Abu-Rahmeh, T.M. (2017) Efficiency of Photovoltaic Modules Using Different Cooling Methods: A Comparative Study. Journal of Power and Energy Engineering, 5, 32-45. https://doi.org/10.4236/jpee.2017.59003

[14] Rodrigo, P.M., Fernández, E.F., Almonacid, F.M. and Pérez-Higueras, P.J. (2017) Quantification of the Spectral Coupling of Atmosphere and Photovoltaic System Performance: Indexes, Methods and Impact on Energy Harvesting. Solar Energy Materials and Solar Cells, 163, 73-90. https://doi.org/10.1016/j.solmat.2017.01.018 
[15] Eke, R., Betts, T.R. and Gottschalg, R. (2017) Spectral Irradiance Effects on the Outdoor Performance of Photovoltaic Modules. Renewable and Sustainable Energy Reviews, 69, 429-434. https://doi.org/10.1016/j.rser.2016.10.062

[16] Duran, E., Piliougine, M., Sidrach-de-Cardona, M., Galan, J. and Andujar, J.M. (2008) Different Methods to Obtain the IV Curve of PV Modules: A Review. 2008 33 rd IEEE Photovolatic Specialists Conference, May 2008, San Diego, 1-6. 